\title{
Gastritis cystica profunda recurrence after surgical resection: 2-year follow-up
}

\author{
Lei Wang ${ }^{1}$, Hua Yan¹, Da-Chun Cao' ${ }^{1}$ Li Huo ${ }^{1}$, Hai-Zhong Huo², Bing Wang ${ }^{2}$, Ying Chen³ and Hai-Lin Liu*
}

\begin{abstract}
Background: Gastritis cystica profunda (GCP) is an uncommon disease characterized by multiple cystic gastric glands within the submucosa of the stomach.

Case description: Here, we present a case of a 63-year-old man with intermittent epigastric discomfort in whom gastroscopy revealed multiple irregular elevated nodular lesions with smooth surfaces at the anterior of the antrum. Surgical resection of the nodular lesions was performed, and the diagnosis of gastritis cystica profunda (GCP) was confirmed by histological examination. Another elevated nodular lesion approximately $10 \mathrm{~mm}$ in diameter with an ulcer was found on the gastric side of the remnant stomach near the resection side from 6 to 24 months after the surgical resection. Endoscopic ultrasonography (EUS) and repeated biopsies of the new elevated lesion were performed. Homogeneous, anechoic masses originating from the submucosa without gastric adenocarcinoma in histological examination showed GCP recurrence may occur.
\end{abstract}

Conclusions: We report a case of GCP recurrence within 6 months after surgical resection. GCP should be considered in the differential diagnosis of elevated lesions in the stomach.

Keywords: Gastritis cystica profunda, Gastric cancer, Endoscopic ultrasonography

\section{Background}

Gastritis cystica profunda (GCP) is an uncommon disease characterized by multiple cystic gastric glands within the submucosa of the stomach. GCP seemed to be limited to previously operated stomachs in prior reports, but it has been found in unoperated stomachs in several recent articles [1-3]. Here, we report a case of GCP that occurred in a patient who had not previously undergone gastric surgery, and the GCP recurred in just 6 months after surgical resection.

\section{Case presentation}

A 63-year-old man was admitted to the gastroenterology department for intermittent epigastric discomfort. He had no history of gastric operations. Blood tests and physical examination showed no abnormalities except the CEA level of serum was $7.68 \mathrm{ng} / \mathrm{mL}$. Gastroscopy revealed multiple irregularly elevated nodular lesions with smooth

\footnotetext{
* Correspondence: liuhailin@medmail.com.cn

'Department of Gastroenterology, the Ninth People's Hospital Affiliated to the School of Medicine, Shanghai Jiaotong University, Shanghai 200011 , China

Full list of author information is available at the end of the article
}

surfaces on the anterior portion of the antrum (Figure 1). Two biopsies revealed normal mucosa. Endoscopic ultrasonography (EUS) showed a hypoechoic mass in the submucosa without clear margins (Figure 2). Abdominal computed tomography showed no significant gastric or perigastric lesions of the stomach.

Exploratory laparotomy was performed with the patient's claiming because malignancy was suspected according to the abnormal CEA level. Two elevated nodular lesions approximately $10 \mathrm{~mm}$ and $15 \mathrm{~mm}$ in diameter were identified in the anterior portion of the antrum during the operation. The nodular lesions were surgically resected. A histological examination showed dilated cystic glands in the muscularis mucosa and submucosa (Figure 3), and a diagnosis of GCP was established.

Follow-up gastroscopies were performed at 6 months, 12 months, and 24 months after the surgical resection, and another elevated nodular lesion approximately $10 \mathrm{~mm}$ in diameter with an ulcer was found on the gastric side of the remnant stomach near the resection side (Figure 4). Another EUS of the new lesion was performed showing several homogeneous, anechoic masses originating from the submucosa (Figure 5). Three repeated biopsies of the 


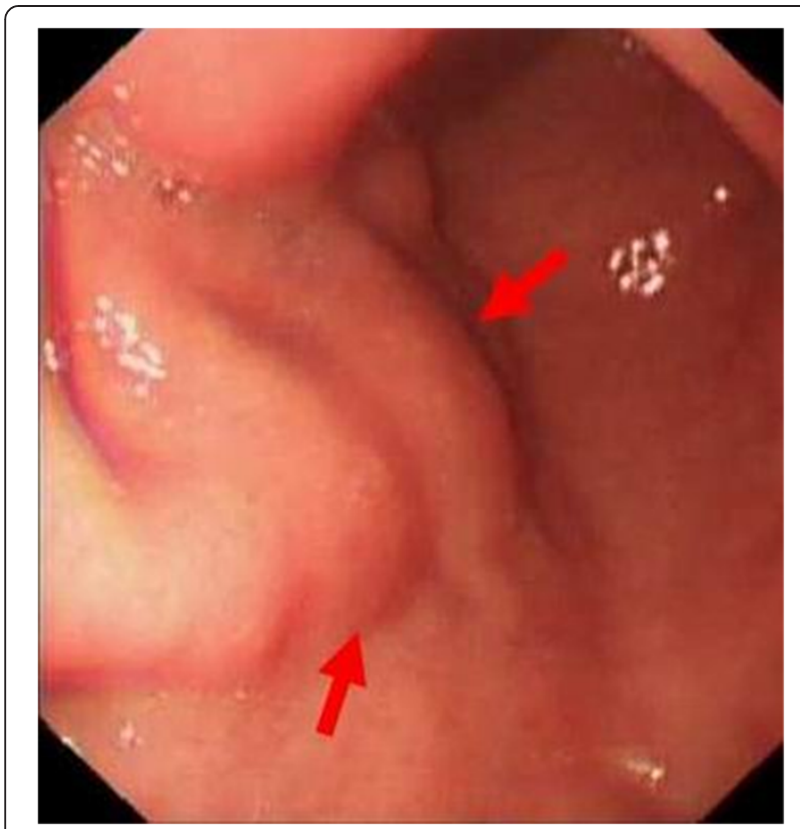

Figure 1 Gastroscopy revealing multiple irregular elevated nodular lesions (arrows) with smooth surfaces in the anterior portion of the antrum.

newly elevated lesion were performed, and histological examination confirmed chronic gastritis without gastric adenocarcinoma. So the GCP recurrence may occur after surgical resection according to the EUS.

\section{Discussion}

GCP is a rare disease that was first described by Littler ER in 1972 [4] and is characterized by multiple cystic gastric glands within the submucosa of the stomach. The lesion usually occurs at gastroenterostomy sites; however, it has also been found in the stomachs of patients who have not previously undergone gastric

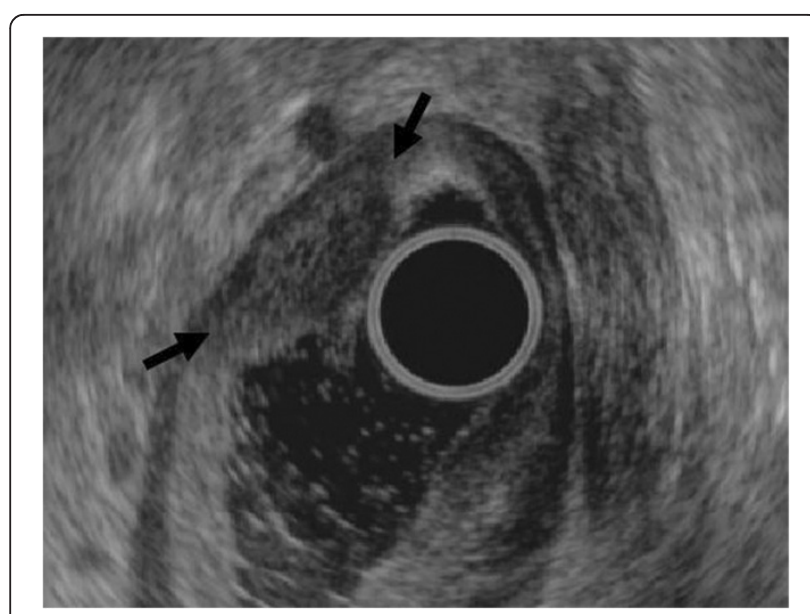

Figure 2 Endoscopic ultrasonography showing a hypoechoic mass without clear margins (arrows) in the submucosa.

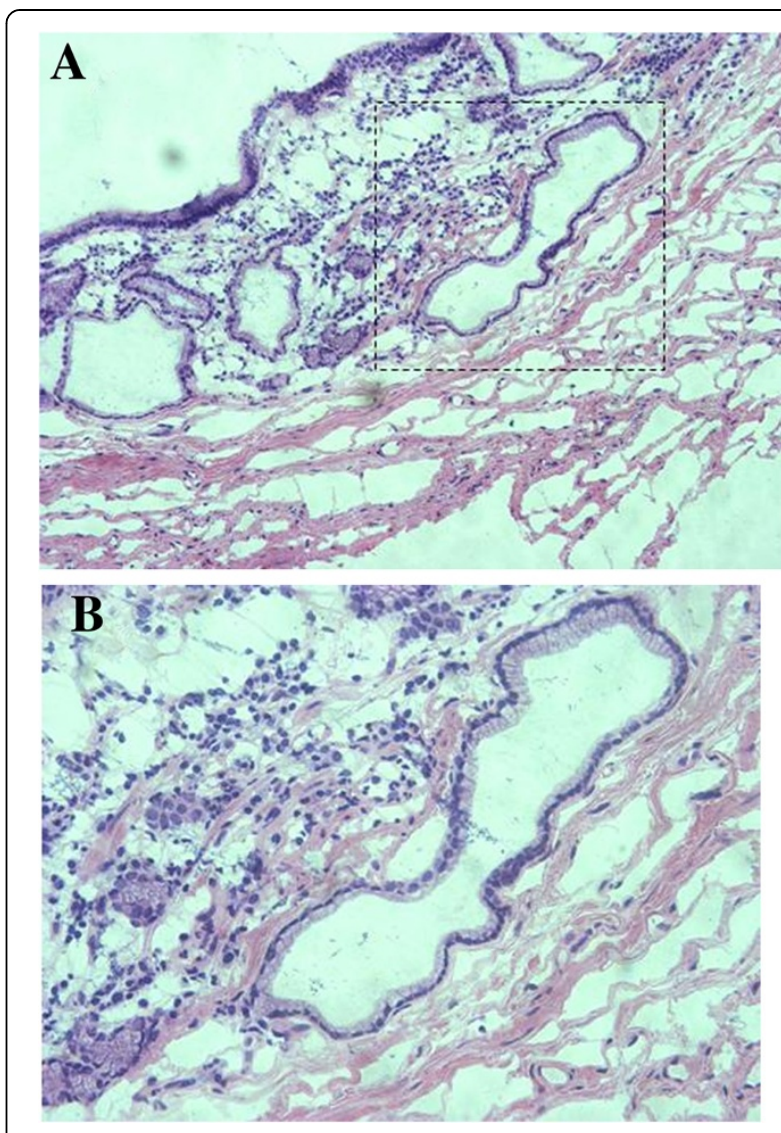

Figure 3 Histological examination of the nodular lesions showing dilated cystic glands in the muscularis mucosa and submucosa (hematoxylin and eosin staining; $(A) \times 100 ;(B) \times 200$ ).

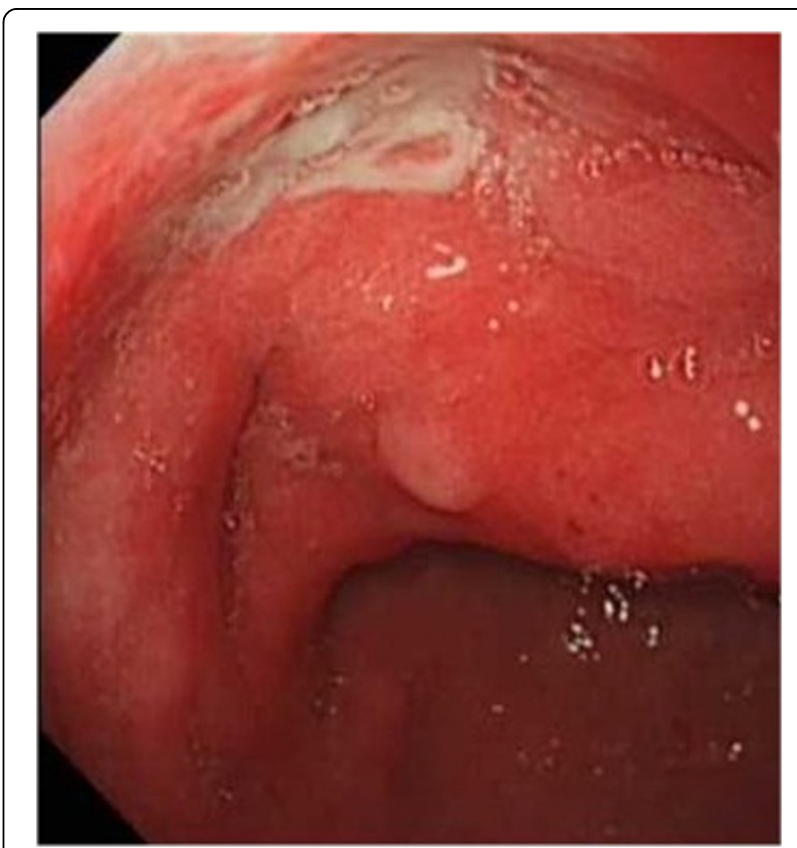

Figure 4 Follow-up gastroscopy at 6 months after the surgical resection finding another elevated nodular lesion with an ulcer on the gastric side of the remnant stomach. 


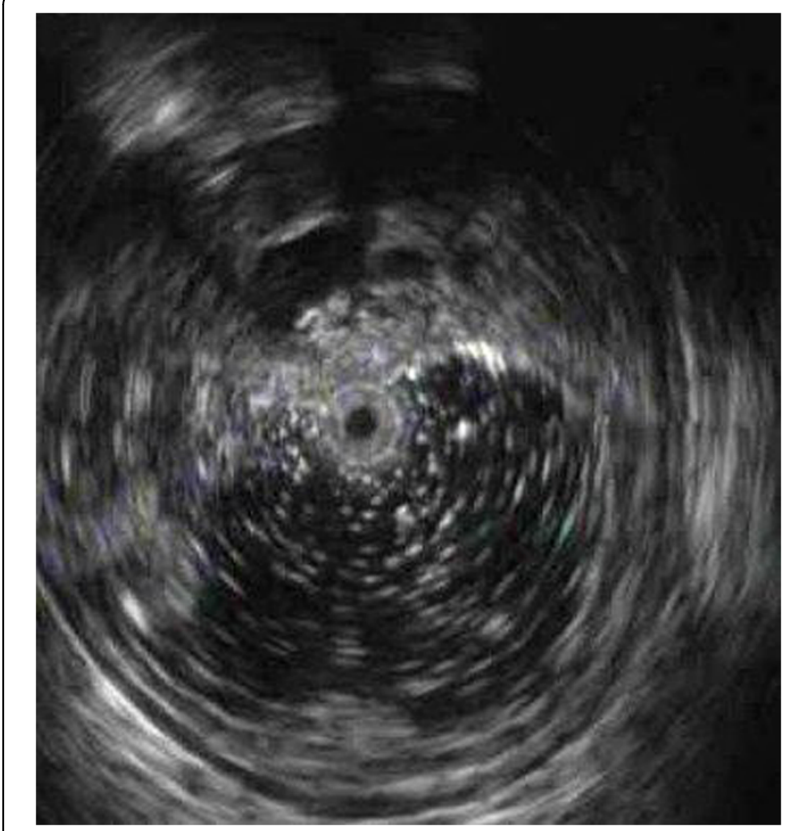

Figure 5 EUS of the new lesion showing several homogeneous, anechoic masses originating from the submucosa.

surgery in several other articles [1-3]. GCP tends to occur more frequently in the presence of gastric cancers $[2,3,5-8]$; in a pathological study of 10,728 patients with gastric cancer, it was found in 161 patients [8]. There are some reports of GCP coexisting with Ménétrier disease (MD) $[9,10]$ or gastric inverted hyperplastic polyps (IHP) [11]. To the best of our knowledge, this report is the first case report of GCP recurrence within a short time after surgical resection.

GCP may present as elevated lesions in gastroscopy and should be differentiated from early gastric cancers, submucosal tumors, giant gastric folds, or polyps. GCP can cause massive upper gastrointestinal hemorrhages in some cases $[12,13]$, and it may be a cause of gastric outlet obstruction when accompanied by adenocarcinoma [3]. EUS revealed a hypoechoic mass without clear margins in the submucosa in the present case, which differs from homogeneous, hypoechoic, and multilocular polypoid masses in other cases [1-3]. The diagnosis of GCP should be confirmed by histological examination.

GCP is usually considered a benign lesion, but it can be a precancerous gastric lesion. Its malignant potential should be valued because GCP accompanied by gastric adenocarcinoma has been documented in several reports [2,3,5-8]. Ten-year follow-up of a case with GCP in an unoperated patient revealed low-grade dysplasia, and the sizes of both the GCP and the adenoma overlying it increased during the follow-up period [14].

The mechanism of GCP is not very clear. Roepke TK et al. [15] demonstrated that targeted deletion of the
Kcne2 gene in mice can cause a severe gastric preneoplastic phenotype comprising GCP. Kim L et al. [16] found that the Epstein-Barr virus (EBV) in situ hybridization revealed a positive reaction at the dysplastic area in a case of GCP associated with gastric carcinoma with lymphoid stroma. Choi MG et al. [8] found that the EBV-positive rate was significantly higher in a GCP gastric cancer group (31.1\%) than in a non-GCP gastric cancer group (5.8\%), which suggested that GCP was significantly associated with EBV-positive gastric cancers and that EBV infection may play a role in dysplastic changes associated with GCP. Mongolian gerbil model animals infected with Helicobacter pylori could develop GCP, gastric ulcers, and focal dysplasia. Additionally, the H. pylori cag-pathogenicity island-dependent immunological response may trigger GCP [17].

\section{Conclusions}

In conclusion, although GCP is extremely rare, it should be considered in the differential diagnosis of elevated lesions in the stomach.

\section{Consent}

Written informed consent was obtained from the patient for the publication of this report and any accompanying images.

\section{Abbreviations \\ EBV: Epstein-Barr virus; EMR: Endoscopic mucosal resection; EUS: Endoscopic ultrasonography; GCP: Gastritis cystica profunda; IHP: Inverted hyperplastic polyp; MD: Ménétrier disease.}

\section{Competing interests}

The authors declare that they have no competing interests.

\section{Authors' contributions}

WL wrote the article; $W L, Y H, C D C$, and $\mathrm{HL}$ did the gastroscopy and endoscopic ultrasonography; $\mathrm{HHZ}$ and $\mathrm{WaB}$ did the operation; $\mathrm{CY}$ did the pathological tests; LHL made the final approval of the article. All authors read and approved the final manuscript.

\section{Acknowledgements}

The study was supported by Shanghai Science and Technology Committee Foundation (10JC1409000).

\section{Author details}

'Department of Gastroenterology, the Ninth People's Hospital Affiliated to the School of Medicine, Shanghai Jiaotong University, Shanghai 200011, China. ${ }^{2}$ Department of Surgery, the Ninth People's Hospital Affiliated to the School of Medicine, Shanghai Jiaotong University, Shanghai 200011, China. ${ }^{3}$ Department of Pathology, the Ninth People's Hospital Affiliated to the School of Medicine, Shanghai Jiaotong University, Shanghai 200011, China.

Received: 12 April 2013 Accepted: 7 April 2014

Published: 30 April 2014

\section{References}

1. Bechade D, Desrame J, Algayres JP: Gastritis cystica profunda in a patient with no history of gastric surgery. Endoscopy 2007, Suppl 1:E80-E81.

2. Moon SY, Kim KO, Park SH, Yoo KS, Park CH, Kim JH, Park CK, Jun SY: Gastritis cystica profunda accompanied by multiple early gastric cancers. Korean J Gastroenterol 2010, 55:325-330. 
3. Matsumoto T, Wada M, Imai Y, Inokuma T: A rare cause of gastric outlet obstruction: gastritis cystica profunda accompanied by adenocarcinoma. Endoscopy 2012, Suppl 2:E138-E139.

4. Littler ER, Gleibermann E: Gastritis cystica polyposa (gastric mucosal prolapse at gastroenterostomy site, with cystic and infiltrative epithelial hyperplasia). Cancer 1972, 29:205-209.

5. Deery S, Yates R, Hata J, Shi C, Parikh AA: Gastric adenocarcinoma associated with gastritis cystica profunda in an unoperated stomach. Am Surg 2012, 78:E379-E380.

6. Odze RD, Greenson J, Lauwers G, Goldblum J: Gastritis cystica profunda versus invasive adenocarcinoma. Am J Surg Pathol 2012, 36:316.

7. Tsuji T, Iwahashi M, Nakamori M, Ueda K, Ishida K, Naka T, Ojima T, Akamatsu H, Yamaue H: Multiple early gastric cancer with gastritis cystica profunda showing various histological types. Hepatogastroenterology 2008 55:1150-1152

8. Choi MG, Jeong JY, Kim KM, Bae JM, Noh JH, Sohn TS, Kim S: Clinical significance of gastritis cystica profunda and its association with Epstein-barr virus in gastric cancer. Cancer 2012, 118:5227-5233.

9. Soares JB, Bastos P, Goncalves R: Menetrier disease with antrum polyposis and gastritis cystica profunda. Endoscopy 2012, Suppl 2:E56-E57.

10. Lim JK, Jang YJ, Jung MK, Ryeom HK, Kim GC, Bae J: Menetrier disease manifested by polyposis in the gastric antrum and coexisting with gastritis cystica profunda. Gastrointest Endosc 2010, 72:1098-1100.

11. Yamashita M, Hirokawa M, Nakasono M, Kiyoku H, Sano N, Fujii M, Koyama T, Yoshida S, Sano T: Gastric inverted hyperplastic polyp report of four cases and relation to gastritis cystica profunda. APMIS 2002, 110:717-723.

12. Kurland J, DuBois S, Behling C, Savides T: Severe upper-Gl bleed caused by gastritis cystica profunda. Gastrointest Endosc 2006, 63:716-717.

13. Itte $\mathrm{V}$, Mallick $I \mathrm{H}$, Moore PJ: Massive gastrointestinal haemorrhage due to gastritis cystica profunda. Cases J 2008, 1:85.

14. Kim JH, Jang SY, Hwang JA, Ha SH, Choi WG, Park JS, Han EM: A ten-year follow-up of a case with gastric adenoma accompanied with gastritis cystica profunda treated by endoscopic submucosal dissection. Korean J Gastroenterol 2012, 59:366-371.

15. Roepke TK, Purtell K, King EC, La Perle KM, Lerner DJ, Abbott GW: Targeted deletion of Kcne2 causes gastritis cystica profunda and gastric neoplasia. PLoS One 2010, 5:e11451.

16. Kim L, Kim JM, Hur YS, Shin YW, Park IS, Choi SJ, Han JY, Chu YC, Kim KH: Extended gastritis cystica profunda associated with epstein-barr virus-positive dysplasia and carcinoma with lymphoid stroma. Pathol Int 2012, 62:351-355.

17. Wiedemann T, Loell E, Mueller S, Stoeckelhuber M, Stolte M, Haas R, Rieder G: Helicobacter pylori cag-pathogenicity island-dependent early immunological response triggers later precancerous gastric changes in mongolian gerbils. PLoS One 2009, 4:e4754.

doi:10.1186/1477-7819-12-133

Cite this article as: Wang et al:: Gastritis cystica profunda recurrence after surgical resection: 2-year follow-up. World Journal of Surgical Oncology 2014 12:133.

\section{Submit your next manuscript to BioMed Central and take full advantage of:}

- Convenient online submission

- Thorough peer review

- No space constraints or color figure charges

- Immediate publication on acceptance

- Inclusion in PubMed, CAS, Scopus and Google Scholar

- Research which is freely available for redistribution 